\title{
CRASHWORTHINESS ANALYSIS OF THE STRUCTURE OF METRO VEHICLES CONSTRUCTED FROM TYPICAL MATERIALS AND THE LUMPED PARAMETER MODEL OF FRONTAL IMPACT
}

\author{
Tao $\mathrm{ZHU}^{1^{*}}$, Shou-Ne XIAO${ }^{2}$, Guang-Zhong $\mathrm{HU}^{3}$, \\ Guang-Wu YANG ${ }^{4}$, Bin YANG ${ }^{5}$, Chao $\mathrm{YANG}^{6}$ \\ 1,2, 4-6Traction Power National Key Laboratory, Southwest Jiaotong University, China \\ ${ }^{3}$ College of Mechanical Engineering, Sichuan University of Science and Engineering, China
}

Received 1 June 2016; revised 24 July 2016, 11 September 2016; accepted 13 September 2016

\begin{abstract}
This paper establishes a Finite Element (FE) model of a rigid barrier impact of a single vehicle constructed from carbon steel, stainless steel, and aluminum alloy, which are three typical materials used in metro vehicle car body structures. The different responses of the three materials during the collision are compared. According to the energy absorption, velocity, deformation and collision force flow characteristics of each vehicle, the relationship between the energy absorption ratio of the vehicle body and the energy absorption ratio of its key components is proposed. Based on the collision force flow distribution proportion of each component, the causes of the key components' deformation are analysed in detail. The internal relationship between the deformation, energy absorption and impact force of the key components involved in a car body collision is elucidated. By determining the characteristic parameters describing the vehicle's dynamic stiffness, a metro vehicle frontal impact model using lumped parameters is established that provides a simple and efficient conceptual design method for railway train safety design. These research results can be used to guide the design of railway trains for structural crashworthiness.
\end{abstract}

Keywords: metro vehicle structures, typical materials, impact response characteristics, collision force flow, intrinsic relationship, lumped parameter model of frontal impact.

\section{Introduction}

In European norms that stress multi-level energy absorption standards and United States norms that regulate the principle of crash energy management, the core goal of the crashworthiness design of vehicles is as follows: introduce an energy-absorbing structure into a car body and reasonably design different regions of the longitudinal stiffness to ensure that controllable ordered deformation during vehicle collision processes mitigates the effect of vehicle collisions and ensures both passenger safety and vehicle structural integrity. Crashworthy vehicles generally adopt a multistage energy-absorbing system to absorb impact energy. Up to the first speed threshold, the coupler buffer device serves a role. Up to the second speed limit, after the coupler buffer device becomes energy-absorption-saturated, the shearing device between the coupler and the under frame is destroyed, the coupler and under frame are separated, and the anti-climbs of the two vehicles are engaged; energy is absorbed by the energy absorption device at the rear end of the anti-climb devices. Up to the third speed limit, the first two techniques of energy absorption reach their limit, and the residual energy is absorbed by the easy deformation zone of the end of the car body, which ensures that the living space of the car body is not affected.

Studies of the passive safety of rail trains generally employ one or more of the following four types of research methods: collision dynamics theory analysis, Finite Element (FE) numerical simulation analysis, multi-body dynamics analysis and crash test analysis. Table 1 compares the research contents, methods, tools, and objectives of these four types of research methods.

Of the four types of research methods, the crash test can accurately reflect the collision scene; however, a large number of sensors and high-speed cameras are needed during the test. This type of work is time-consuming. In addition, testing is generally destructive with poor performance and a high cost. Train collision dynamics the-

${ }^{\star}$ Corresponding author. E-mail: zhutao034@swjtu.cn 
ory and the train collision multi-body dynamics method focus on the study of train instability response and the relationship among the dynamic actions of the train. The FE simulation has become one of the most commonly employed structural design and verification methods due to its accurate results, strong operability, short period and minimal influence from the external environment. Currently, computer simulation has been able to model train collisions with the development of computer hardware/ software technology and highly nonlinear FE technology. Without the use of other external auxiliary systems, computer simulations can obtain more detailed characteristics of structural collision behaviour than actual test methods by structural modelling, the establishment of boundary conditions, and time step control.

International research on locomotive and rolling stock crashworthiness accelerated in the 1980s. Based on the statistics and research on train collisions and reconstruction of typical train collisions, Britain, France, Germany, the United States and many other countries have successively developed technical specifications and standards for the passive safety protection of multiple track vehicles - e.g., British railway group standards GM/RT2100 (RSSB 2012), technical specification for European railway interconnection (EC 2002), American railroad association standards (AAR S-580-2005), and European standards (DIN EN 15227:2008). The collision scene setting and evaluation index of the FE simulation regarding locomotive and rolling stock are obtained from these specifications and standards.

The majority of the collision kinetic energy of rail vehicles needs to be absorbed by the easy deformation zone at the end of a car body to protect the survival of the car body and guarantee passenger safety. Therefore, the structural crashworthiness of the deformation zone at the end of a car body should be designed and verified. Xue et al. (2005) investigated the crashworthiness of a head vehicle, concluding that the downward bending deformation was the innate weakness of a rail vehicle collision and that folding was the main failure mode of the structure. The

Table 1. Collision safety methods of rail vehicle car bodies

\begin{tabular}{|c|c|c|c|c|}
\hline No & Classification & Research contents & Methods and tools & Results \\
\hline \multirow{3}{*}{1} & \multirow{3}{*}{$\begin{array}{l}\text { Train collision } \\
\text { dynamics } \\
\text { theory }\end{array}$} & $\begin{array}{l}\text { Energy absorption element } \\
\text { (coupler and buffer device, } \\
\text { energy absorption and anti- } \\
\text { climb device, etc.) }\end{array}$ & Simplified numerical analysis & $\begin{array}{l}\text { Basic design parameters of energy } \\
\text { absorption element }\end{array}$ \\
\hline & & $\begin{array}{l}\text { One-dimensional (1D) train } \\
\text { collision dynamics }\end{array}$ & Multi-body dynamics program & $\begin{array}{l}\text { Train longitudinal collision rules; } \\
\text { Longitudinal stiffness design of car body }\end{array}$ \\
\hline & & $\begin{array}{l}\text { Three-dimensional (3D) train } \\
\text { collision dynamics }\end{array}$ & Multi-body dynamics program & $\begin{array}{l}\text { Design principle of coupler and buffer } \\
\text { device; } \\
\text { Analysis of load and energy level } \\
\text { of energy absorption area of vehicle; } \\
\text { Average reduction rate analysis }\end{array}$ \\
\hline \multirow{3}{*}{2} & \multirow{3}{*}{$\begin{array}{l}\text { Detailed } \\
\text { dynamic } \\
\text { analysis of } \\
\text { vehicle crash } \\
\text { characteristics }\end{array}$} & $\begin{array}{l}\text { Design analysis and } \\
\text { experimental verification of } \\
\text { energy-absorbing element }\end{array}$ & $\begin{array}{l}\text { Nonlinear FE analysis; } \\
\text { Quasi-static test; } \\
\text { Dynamic test }\end{array}$ & $\begin{array}{l}\text { Design conditions and basic parameters } \\
\text { of energy absorption element; } \\
\text { Load-deformation characteristic curves; } \\
\text { Validation of simulation models }\end{array}$ \\
\hline & & $\begin{array}{l}\text { Design and analysis of collision } \\
\text { energy absorption zone }\end{array}$ & $\begin{array}{l}\text { FE quasi-static analysis; } \\
\text { FE dynamic analysis }\end{array}$ & Load-deformation characteristic curves \\
\hline & & $\begin{array}{l}\text { Analysis of the characteristics } \\
\text { of train collision }\end{array}$ & FE impact analysis software & $\begin{array}{l}\text { Deformation characteristics; } \\
\text { Acceleration; } \\
\text { Safety assessment of train collision; }\end{array}$ \\
\hline 3 & $\begin{array}{l}\text { Multi-body } \\
\text { dynamics } \\
\text { simulation of } \\
\text { train collision }\end{array}$ & $\begin{array}{l}\text { Multi-body dynamics simulation } \\
\text { of train collision }\end{array}$ & $\begin{array}{l}\text { Multi-body dynamics } \\
\text { analysis software (based on } \\
\text { the characteristics of energy } \\
\text { absorption element, energy } \\
\text { absorption characteristics } \\
\text { of the deformation zone } \\
\text { of the vehicle body end) }\end{array}$ & $\begin{array}{l}\text { Design principle of coupler and buffer } \\
\text { device; } \\
\text { Characteristics of train collision course; } \\
\text { Force, velocity, acceleration }\end{array}$ \\
\hline \multirow[t]{2}{*}{4} & \multirow[t]{2}{*}{ Crash test } & $\begin{array}{l}\text { End structures (include: coupler } \\
\text { and buffer device, energy } \\
\text { absorption and anti-climb } \\
\text { device, and energy absorption } \\
\text { zone) crash test }\end{array}$ & $\begin{array}{l}\text { Quasi-static test; } \\
\text { Dynamic test }\end{array}$ & $\begin{array}{l}\text { Energy distribution at all levels in } \\
\text { the end deformation zone of vehicle; } \\
\text { Deformation characteristics; } \\
\text { Force, velocity, acceleration; } \\
\text { Verification of simulation results }\end{array}$ \\
\hline & & Vehicle crash test & $\begin{array}{l}\text { Quasi-static test; } \\
\text { Dynamic test }\end{array}$ & $\begin{array}{l}\text { Dynamic response of train collision; } \\
\text { Deformation characteristics; } \\
\text { Force and acceleration; } \\
\text { Verification of simulation results }\end{array}$ \\
\hline
\end{tabular}


responses and locations of weakness of the head vehicle and the middle vehicles in the same collision scenarios were compared, and three different collision behaviours of the head and middle vehicle were obtained, including different collision interfaces, different body structures and different collision sequences; structural improvement schemes were also investigated in their research (Xue et al. 2007). Hosseini-Tehrani and Nankali (2010) noted that the head design of a high-speed train should not only consider the aerodynamic performance and noise but also the crashworthiness. The crashworthiness of 19 different internal/external structures and the sizes of head forms were systematically analysed. The results indicated that a slender head structure provides better impact resistance. In addition, the crashworthiness of multi-layer head structures and the head structures with an intermediate foam sandwich were investigated in their research. Hosseini-Tehrani and Bayat (2011) also investigated the optimum design method for crashworthiness of the end of a wagon trapezoid frame. They proposed the combination schemes of a variety of end energy absorption and deformation triggering structures. They noted that the optimal distribution of the end structural material can be obtained from the crashworthiness optimum design to ensure the maximum energy absorption of the end structure and minimize the collision deceleration. Baykasoğlu et al. (2011) evaluated the structural crashworthiness of a railway vehicle after impact with a rigid barrier at $90 \mathrm{~km} / \mathrm{h}$ by simulation and proposed a modified scheme to mitigate structural damage that increased the energy absorption capacity of the end structure by $13 \%$ and rendered plastic deformation more predictable. Baykasoğlu et al. (2012) compared the collision characteristics of the same structures of the middle vehicles, which were composed of aluminum alloy and carbon steel. The results indicated that the structural failure modes of the two vehicles were similar. The former modes in the first four natural frequencies were smaller than the latter modes, but their modes of vibration were consistent. Although the car body weight of the aluminum alloy structure was one-third that of the carbon steel body structure, its stiffness and collision energy absorption rate were within the acceptable range. Using American standards, Gao and Tian (2007) simulated the response of 25 types of passenger vehicles to an impact with a rigid barrier and improved locations of weakness of the end structure, which achieved excellent results in crashes. Xiao et al. (2014) proposed a simulation method that employed a discrete beam to simulate the characteristics of couplers and buffers and investigated their dynamic characteristics, the energy absorption rate and the end structural crashworthiness in a train collision that used a six-section marshalling subway train in a $36 \mathrm{~km} / \mathrm{h}$ collision as a case study. Hou et al. (2007) presented a design of regular hexagonal thin-walled columns for different sectional profiles, which provided a method for the structural design of a car body for enhanced crashworthiness.
From this literature review, the weak position identification and improvements for the car body structure of a rail vehicle are based on the relevant technical standards and crash standards, which can be achieved using an FE model of the structure as a carrier. The ultimate goal is achieved by reasonably designing the ends of structures to ensure that the vehicle structure is destroyed in a predetermined sequence during the collision. The majority of previous studies have focused on energy absorption devices of different materials or the energy-absorbing structures of vehicles. Few studies have investigated the crash characteristics and performance of an entire vehicle structure with different materials. This study investigates the crashworthiness of typical metro vehicles constructed from three different materials (carbon steel, stainless steel, or aluminum alloy) by an analysis of these three types of models of the collision response and the collision force transfer rules to extract the weak locations of the structures and provide guidance for engineering design. By summarizing the structural collision characteristics of three typical metro vehicles, the car body's dynamic stiffness is extracted, and the lumped parameter model is established, which provide a simple and efficient conceptual design method for conducting a frontal collision simulation of a metro vehicle.

\section{Technology and structures of three typical materials of a metro car body}

The metro vehicles in China can be divided into three categories according to the materials in the car body: a carbon steel car body, an aluminum alloy car body or a stainless steel car body. The car body structures and welding processes for these three materials are different. The plates of a stainless steel car body, whose thickness ranges between 0.6 and $4 \mathrm{~mm}$, are the thinnest of these three materials; they are connected by spot welding. Large-scale hollow extrusion aluminum welding and plate-beam combined full welding are commonly employed in aluminum alloy and carbon steel bodies, respectively.

Figures 1 and 2 provide cost information concerning car body maintenance and the total cost (the total cost includes the manufacturing costs and the maintenance costs) in Japan for the three materials. These figures reveal a large difference between the welding process and the manufacturing cost among the different body materials.

The structures of the different modules of a car body, which are designed to satisfy the basic performance requirements of the vehicle, also differ among the three materials. For example, the existing sidewall module of a car body can be divided into the frame type, the truss type and the grid type; the underframe module will also change. Due to changes in these structures, a train can respond differently to vertical, horizontal and vertical loads and exhibit advantages and disadvantages in terms of crashworthiness. Therefore, it is necessary to study the structural response characteristics of the different structures and materials of metro vehicles. 


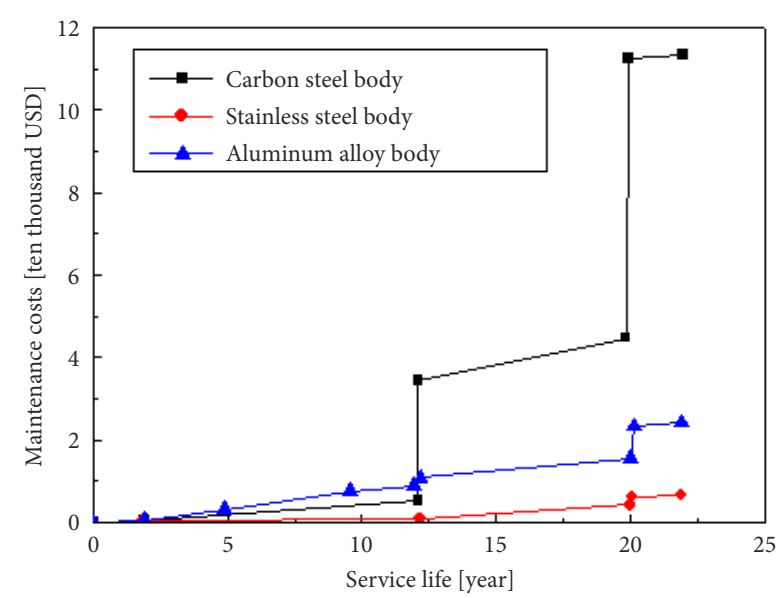

Figure 1. Maintenance costs of car body

\subsection{Establishment of the crash FE models}

This paper selects three typical metro vehicles as the analysis objects, namely, type A, type $\mathrm{B}$, and type $\mathrm{C}$ models. The car body structure of a type A vehicle is composed of welded carbon steel, the car body structure of a type $B$ vehicle is composed of spot-welded stainless steel, and the car body structure of a type $\mathrm{C}$ vehicle is composed of welded aluminum. The three types of car body structures and their materials are listed in Table 2.

The material of the crash FE models is represented by material 3 in LS-DYNA, which is a bilinear kinematic hardening material. Shell 163 is adopted to simulate the car body structure, Mass 166 is used to simulate the masses, and Beam 161 is used to simulate the beam elements. The element size ranges $8 \ldots 15 \mathrm{~mm}$ at the end of the car body; in the middle of the compartment structure, the ele-

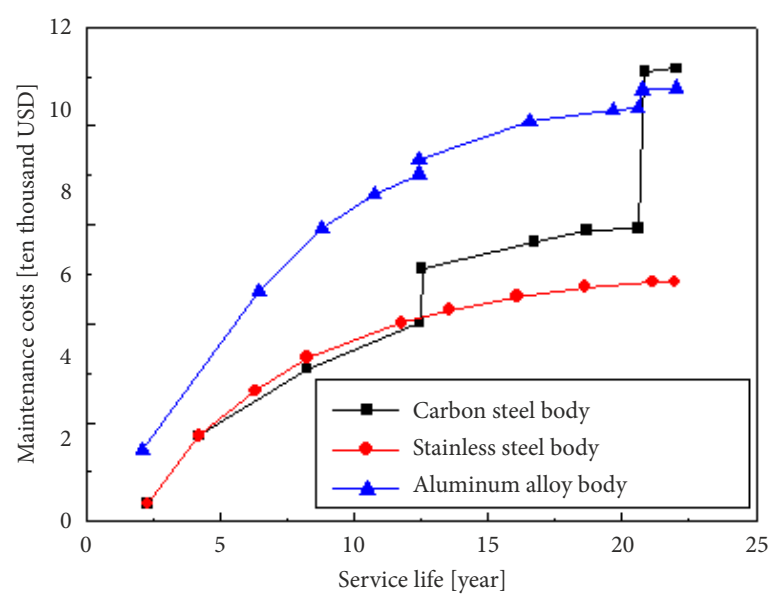

Figure 2. Total cost of car body

ment size is $25 \mathrm{~mm}$. To ensure its strong rigidity, the bogie frame is equivalent to a rigid body; rigid material 20 is chosen as its material. Considering, that the train does not execute any braking measures, the wheel/rail contact dynamic and static friction coefficients are 0.1 , and the other static and dynamic friction coefficients are 0.2 and 0.15 , respectively. The FE models are displayed in Table 2.

\subsection{Evaluation of vehicle crashworthiness}

The passive safety of trains has been investigated through intensive research, especially in the European countries, the United States and other countries, through numerous major train crash research projects. The criteria used to evaluate crashes of rail vehicles include DIN EN 15227:2008, GM/RT2100 (RSSB 2012), EC (2002), 49 CFR Part 229...238. From the requirements of the standards

Table 2. Comparison of three typical car body structures and materials

\begin{tabular}{|c|c|c|c|c|}
\hline & Structures of car body & End structures of underframe & FE models & Materials \\
\hline Type A & & & & $\begin{array}{l}\text { Q355GNH } \\
\text { Q310GNH } \\
\text { Q295GNHJ } \\
\text { Q235B }\end{array}$ \\
\hline Type B & & & & $\begin{array}{l}\text { X2CrNiN18 } \\
\text { S500MC }\end{array}$ \\
\hline Type C & & & & $\begin{array}{l}\text { 6005A-T6 } \\
6082-\mathrm{T} 6\end{array}$ \\
\hline
\end{tabular}


for a crashworthy train providing passive safety, these criteria assess the longitudinal load capacity and vertical load capacity of a car body and provide the specific requirements for energy absorption, impact resistance, and acceleration. However, these assessment indicators are primarily targeted at high-speed trains. For the metro vehicles in this paper, European standard DIN EN 15227:2008 is clearly defined: they belong to the C-II type and represent two groups of vehicles that crash at $25 \mathrm{~km} / \mathrm{h}$. To simplify the calculation mode and improve the computational efficiency, three types of metro vehicles impact with a fixed rigid barrier were analysed, and the structural crashworthiness characteristics were investigated.

\section{Comparison and analysis of structural crashworthiness based on collision simulation}

\subsection{Structural crashworthiness of type A vehicle}

Figure 3 shows the speed change of the gravity center on a type A vehicle during impact with a fixed rigid barrier at a speed of $25 \mathrm{~km} / \mathrm{h}$. The vehicle speed is reduced from 25 to $0 \mathrm{~km} / \mathrm{h}$, and the vehicle subsequently moves in the opposite direction at $2.1 \mathrm{~km} / \mathrm{h}$. Figure 4 shows the deformation of the car body end at the end of the collision. From the view of the collision process, the end of the car body undergoes a large deformation after impact with the rigid wall. A large fold is observed in the corners of the door, the connection joint of the draft beam and end beam, and the connection joint of the draft beam and the body bolster. This response is attributed to the fact that the draft beam is longer along the longitudinal direction than the inclined bracing beam; thus, a large rotation occurs in the connection joint of the end beam and the body bolster, the entire traction seat rotates around the lateral axis, and the draft beam absorbs part of the impact energy during the process.

Figure 5 shows the energy absorption characteristic curve of the entire vehicle body. The body structure rapidly absorbs energy at the initial collision and reaches energy absorption saturation at the end of the collision. The energy absorption characteristics of the curve are gradual, and the total energy absorption is $798.57 \mathrm{~kJ}$. The collision deformation and energy absorption of the vehicle are primarily determined by the end structure of the car body. During a collision, the force is transmitted to the rear end of the car body by the collision interface, and the direction and the manner of the collision load transfer are the main reasons for the deformation of the car body. To demonstrate the transfer path of the impact force in the body, we define the section force-sensing unit of the body, as shown in Figure 6, which is used to analyse the collision force transmission mode and the transfer values.

The collision force transfer characteristic curves of the roof, sidewall and underframe of one section are shown in Figure 7 (only the first $60 \mathrm{~ms}$ of data is shown) The figure also depicts the collision force transfers to the roof,

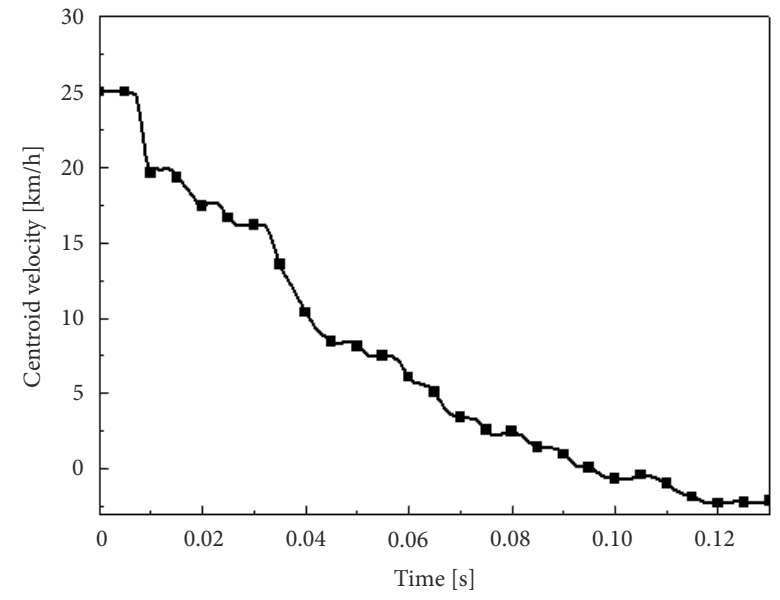

Figure 3. Speed change of gravity center of the vehicle

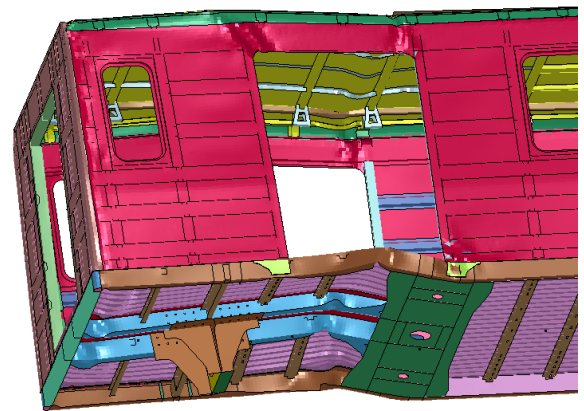

Figure 4. Deformation at end of collision

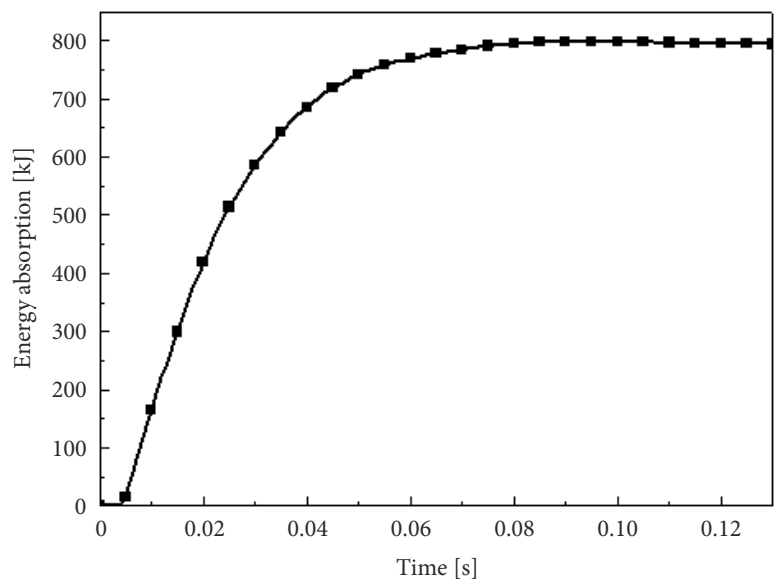

Figure 5. Energy absorption characteristic curve of the vehicle

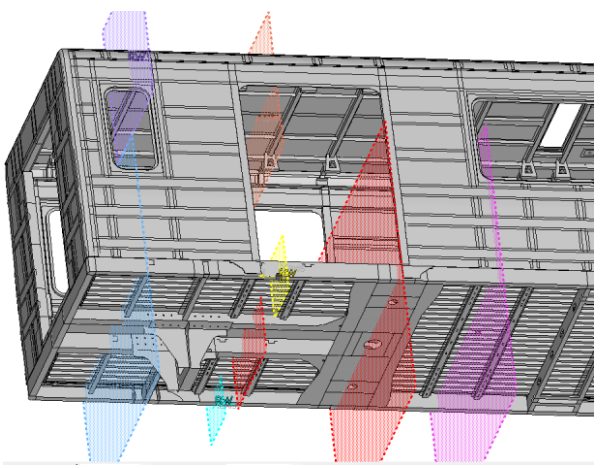

Figure 6. Section force-sensing unit position on the car body 
sidewall and underframe after the vehicle crashes into the rigid wall; the collision force is distributed according to the structural characteristics of each module. To analyse each curve, we obtain the transfer path of the total collision force along the longitudinal direction of the car body and its distribution ratio, which are shown in Figure 8. The transfer path of the collision force in the car body for a type A vehicle can be approximately divided into three layers: for the upper roof, the collision force is directed from the roof edge beam to the roof center sill and to the roof plate. The collision force transfer rate ranges approximately $15 \ldots 25 \%$. For the middle sidewall, the collision force is directed from the sidewall frame to the sidewall panel; the collision force transfer rate is approximately $15 \ldots 25 \%$. For the lower underframe, the collision force is directed from the underframe edge beam to the draft and body bolster beam. For the underframe floor, the collision force transfer rate is approximately $50 . . .70 \%$.

From the transfer ratio of the collision force point, the underframe is the main collision force transfer path. In terms of the collision force point, the underframe best represents the variation over time of the vehicle collision force characteristics. Because the collision force flow of the sidewall in Section 2 is affected by the door, it is transferred to the roof and the underframe, which enables the underframe and the roof to bear a larger impact force.

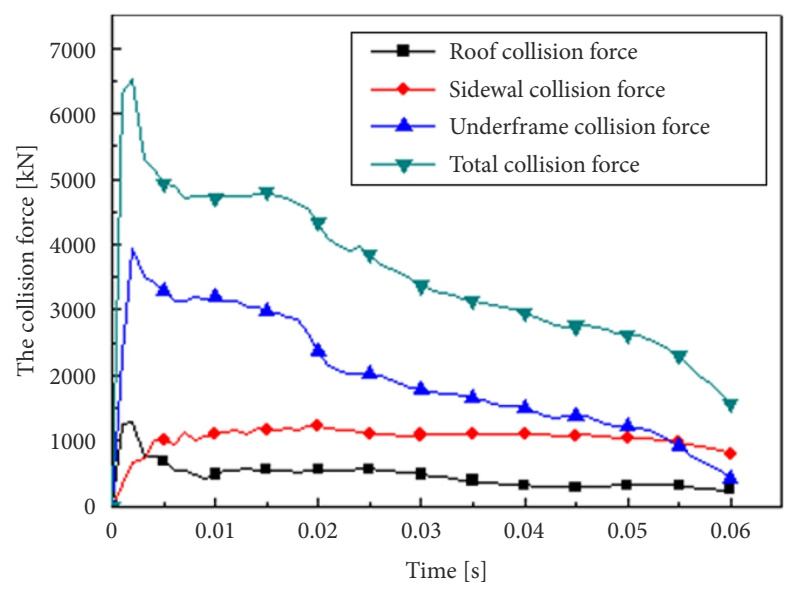

Figure 7. Transfer characteristic curve of the collision force

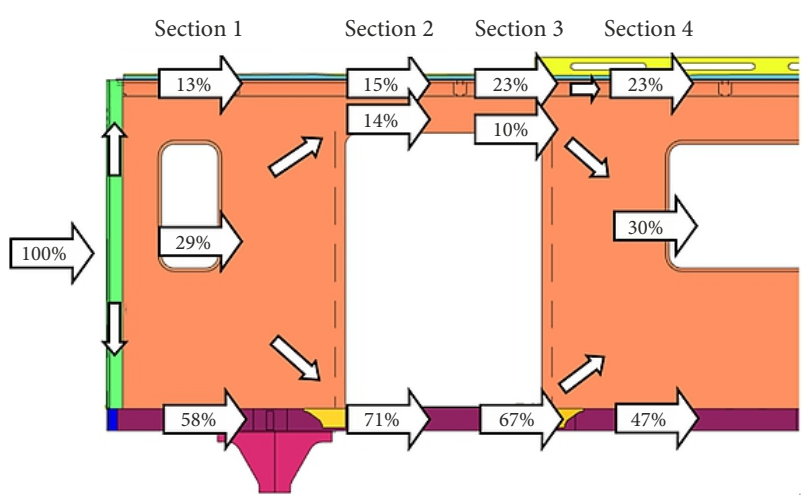

Figure 8. Transfer path distribution of the collision force

\subsection{Structural crashworthiness of type B vehicle}

Figure 9 shows the speed change in the gravity center of a type B vehicle during impact with a fixed rigid barrier at a speed of $25 \mathrm{~km} / \mathrm{h}$. The vehicle speed is reduced from 25 to $0 \mathrm{~km} / \mathrm{h}$, and the vehicle subsequently moves in the opposite direction at $3.2 \mathrm{~km} / \mathrm{h}$. Figure 10 provides the deformation of the car body end at the end of the collision. From the viewpoint of the collision process, the end of the car body undergoes a large deformation after impact with the rigid wall, especially the edge beam, the connection joint of the draft beam and the buffer fitting seat; additionally, the connection joint of the draft beam and the body bolster undergo substantial folding. This deformation is due to the pre- and post-draft beam connection by the coupler box and body bolster, which differ from the traditional draft beam-body bolster-buffer beam structure. At the joint of the body bolster and buffer beam, two pipe holes exist, which cause a large rotation and form a plastic hinge. The traction beam is in a position to absorb impact energy, and the draft beam absorbs a large amount of the impact energy during the process.

Figure 11 shows the energy absorption characteristic curve of the vehicle. The body structure rapidly absorbs energy during the initial collision, the curve slope is large, and the car body exhibits a slight rebound due to elastic energy storage at the end of the collision. The energy absorption curve is gradual, and the energy absorption of the car body reaches saturation; the total absorption energy is $655.1 \mathrm{~kJ}$. We also define the section force-sensing unit of the body, as shown in Figure 12, which is used to analyse the collision force transmission mode and the transfer values.

The collision force transfer characteristic curves of the roof, sidewall and underframe for one section are shown Figure 13, which indicates the collision force transfer to the roof, sidewall and underframe after the vehicle crashes into the rigid wall. Due to the existence of a flanging structure with a length of approximately $70 \mathrm{~mm}$ in the sidewall along the transverse section of the car body, the sidewall becomes the main load-bearing structure within $10 \mathrm{~ms}$ of the start of the collision. From 10 to $60 \mathrm{~ms}$, the underframe serves as the main load-bearing structure; its section force represents a change in the overall trend, and the total collision force also changes. To address each curve, we obtain the transfer path of the total collision force along the longitudinal direction of the car body and its distribution ratio, which are shown in Figure 14. The transfer path of the collision force in the car body of a type $B$ vehicle is consistent with the transfer path of the collision force in the car body of a type A vehicle and can be approximately divided into three layers with collision force transfer rates ranges of $15 \ldots .35,0 \ldots 40$ and $30 \ldots 60 \%$.

In terms of the transfer ratio over time and the collision forces, a type B vehicle and type A vehicle can be concluded to exhibit a similar structural response to this type of collision. 


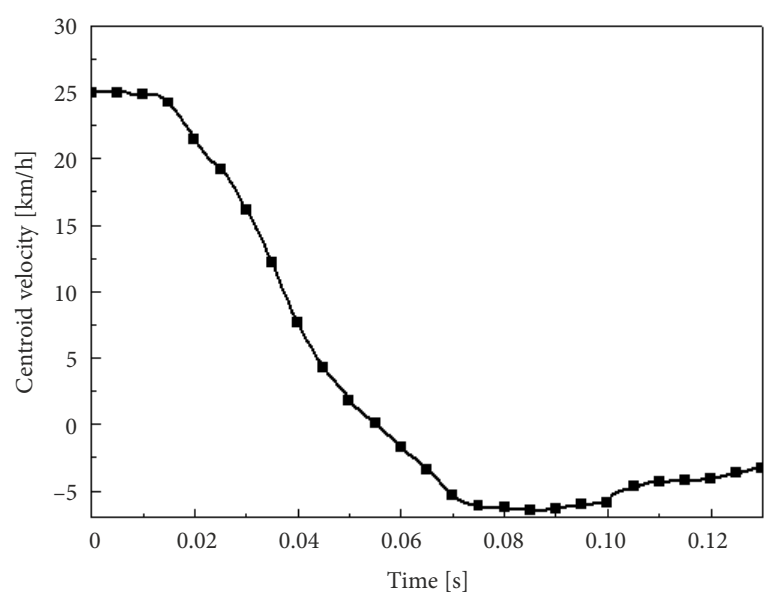

Figure 9. Speed change of gravity center of the vehicle

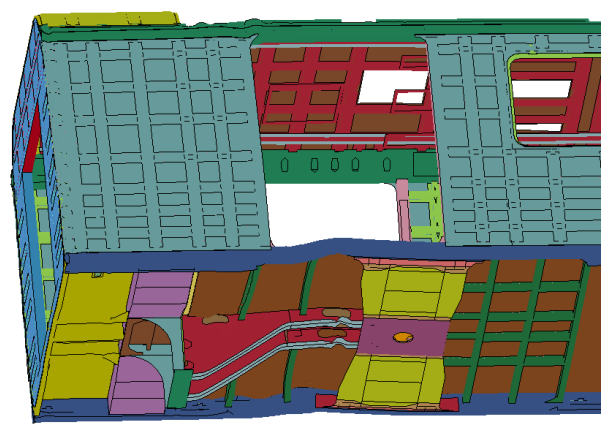

Figure 10. Deformation at end of collision

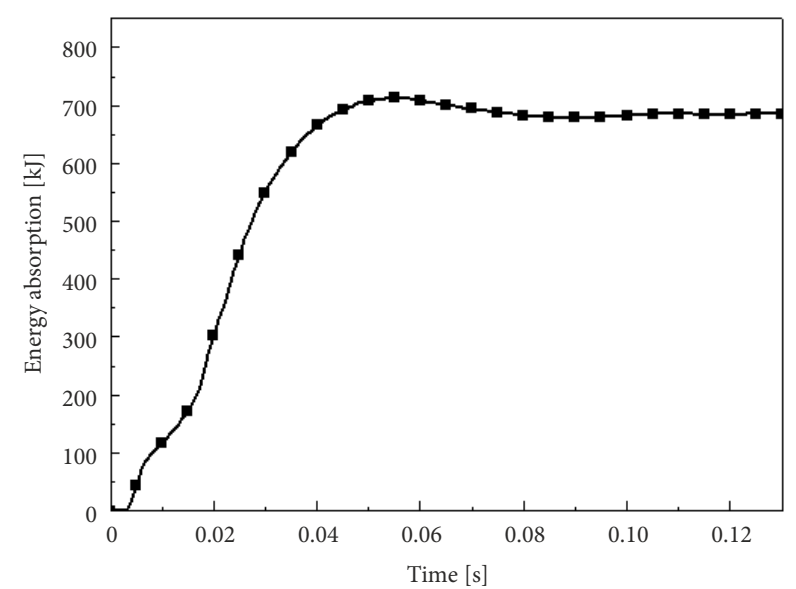

Figure 11. Energy absorption characteristic curve of the vehicle

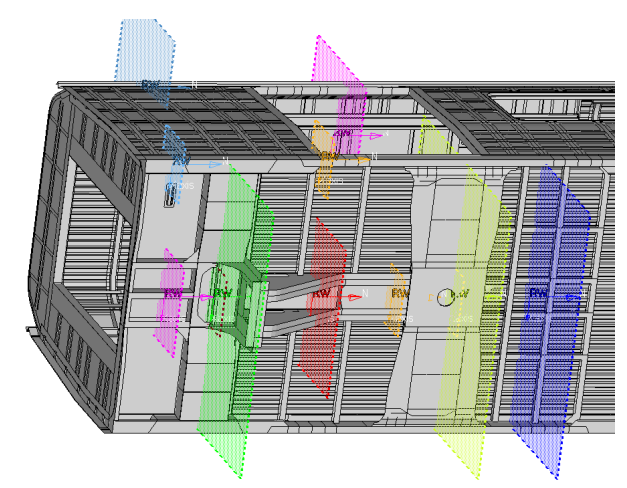

Figure 12. Section force-sensing unit position on the vehicle body

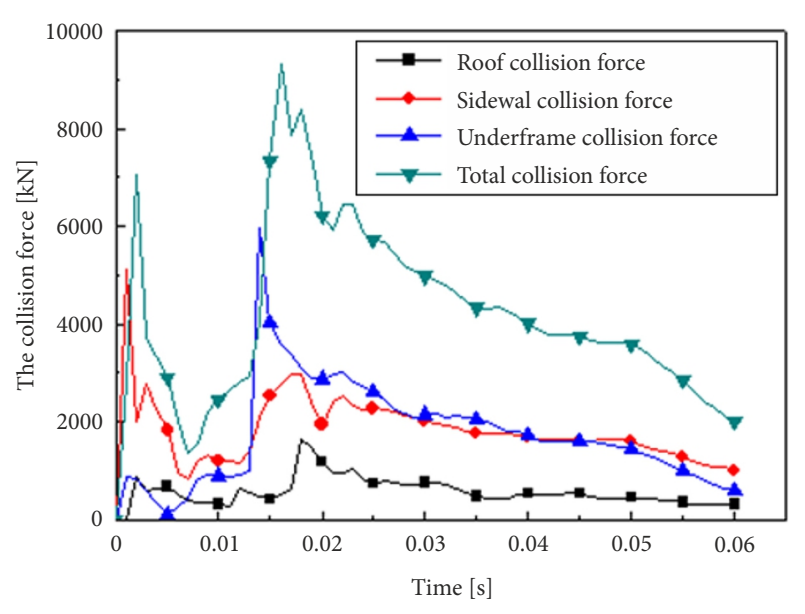

Figure 13. Transfer characteristic curve of the collision force

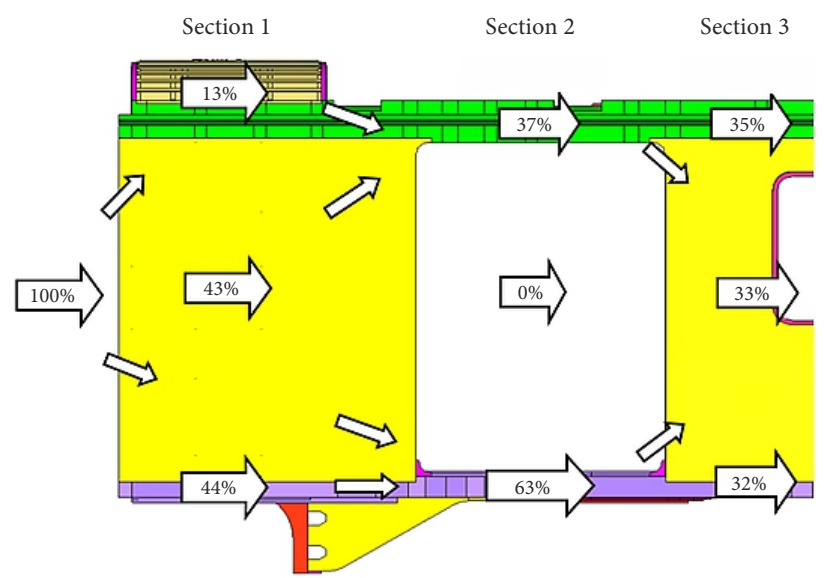

Figure 14. Transfer path distribution of the collision force

\subsection{Structural crashworthiness of type $C$ vehicle}

Figure 15 shows the speed change of the gravity center of a type $\mathrm{C}$ vehicle during impact with a fixed rigid barrier at a speed of $25 \mathrm{~km} / \mathrm{h}$. The vehicle speed is reduced from 25 to $0 \mathrm{~km} / \mathrm{h}$, and the vehicle subsequently moves in the opposite direction at $9.5 \mathrm{~km} / \mathrm{h}$. Figure 16 shows the deformation of the car body end at the end of the collision. From the viewpoint of the collision process, the end of the car body undergoes a large deformation after the vehicle collides with the rigid wall, especially the edge beam, the connection joint of the draft beam and the body bolster; additionally, the connection joints of the endwall and sidewall undergo considerable folding. This deformation arises because the underframe structure is welded by the modules of the corrugated plates. The draft beam-body bolster-buffer beam structure is also a contributing factor; the end of the draft beam is weaker than the end of the draft beam in other structures, which causes a large rotation and forms a plastic hinge, positioning the traction beam to absorb part of the impact energy.

Figure 17 shows the energy absorption characteristic curve for the vehicle. The body structure rapidly absorbs energy at the initial collision, the curve slope is large, and the car body rebounds slightly due to the elastic energy 


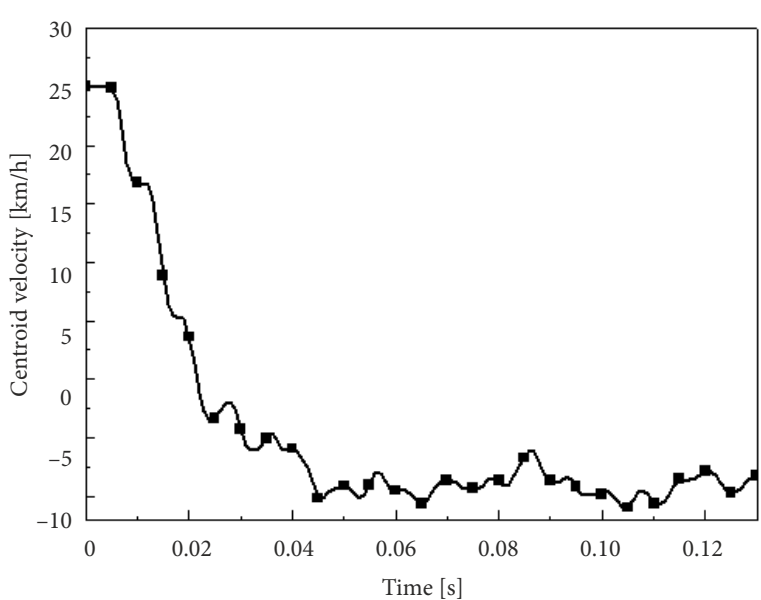

Figure 15. Speed change of the gravity center of the vehicle

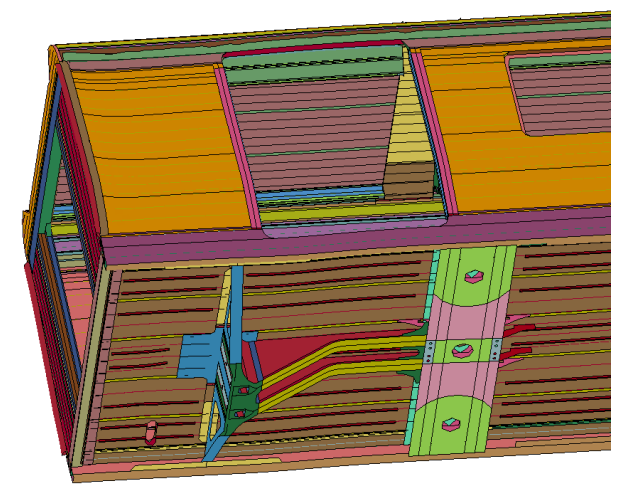

Figure 16. Deformation at the end of the collision

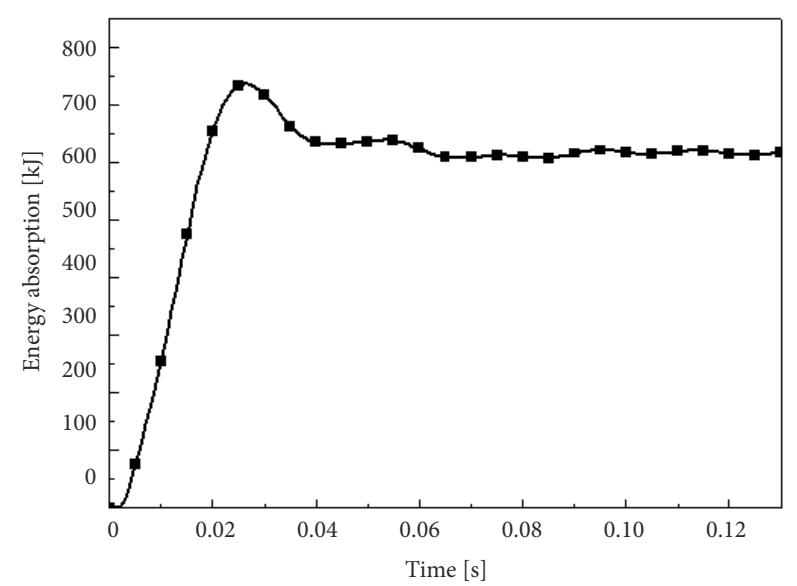

Figure 17. Energy absorption characteristic curve of the vehicle

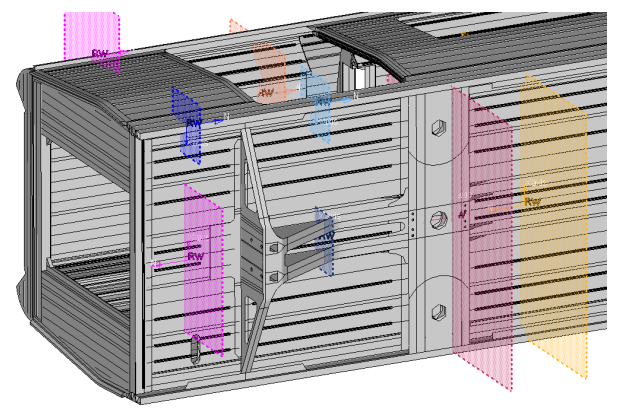

Figure 18. Section force-sensing unit position on the car body storage at the end of the collision. The energy absorption curve is gentle, and the energy absorption of the car body reaches saturation; the total absorption energy is $610.87 \mathrm{~kJ}$. We also define the section force-sensing unit of the body, as shown in Figure 18, which is used to analyse the collision force transmission mode and the transfer values.

The collision force transfer characteristic curves of the roof, sidewall and underframe for one section are shown in Figure 19. The collision force transfer to the roof, sidewall and underframe after the vehicle collides with the rigid wall is also depicted. Due to the existence of a flanging structure with a length of approximately $40 \mathrm{~mm}$ at the sidewall along the transverse section of the car body, the sidewall is the main load-bearing structure within $10 \mathrm{~ms}$ of the start of the collision. From 10 to $60 \mathrm{~ms}$, the underframe is the main load-bearing structure; its section force becomes the dominant factor, and the total collision force also changes. To address each curve, we obtain the transfer path of the total collision force along the longitudinal direction of the car body and its distribution ratio, which are shown in Figure 20. The transfer path of the collision force in the car body of a type $\mathrm{C}$ vehicle can be approximately divided into three layers: for the upper roof in the roof integrated module, the collision force transfer rate ranges approximately $10 \ldots 17 \%$; for the middle side-

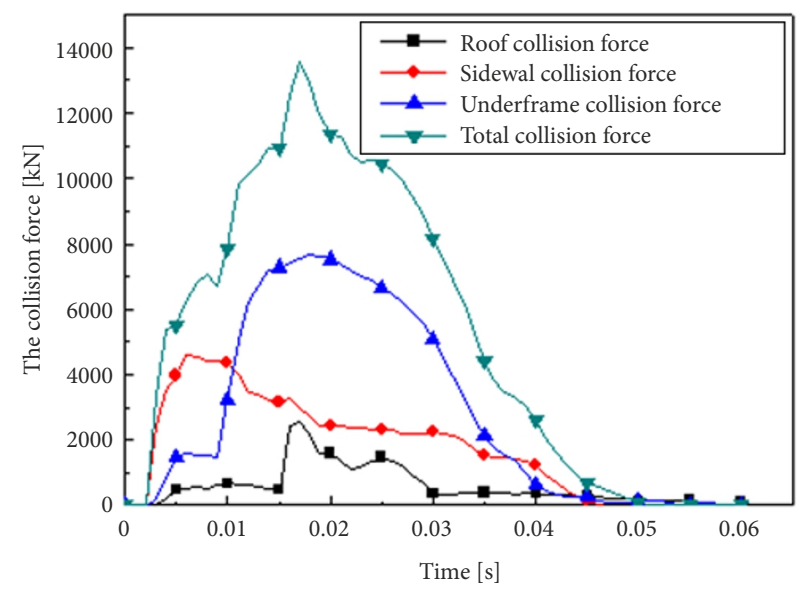

Figure 19. Transfer characteristic curve of the collision force

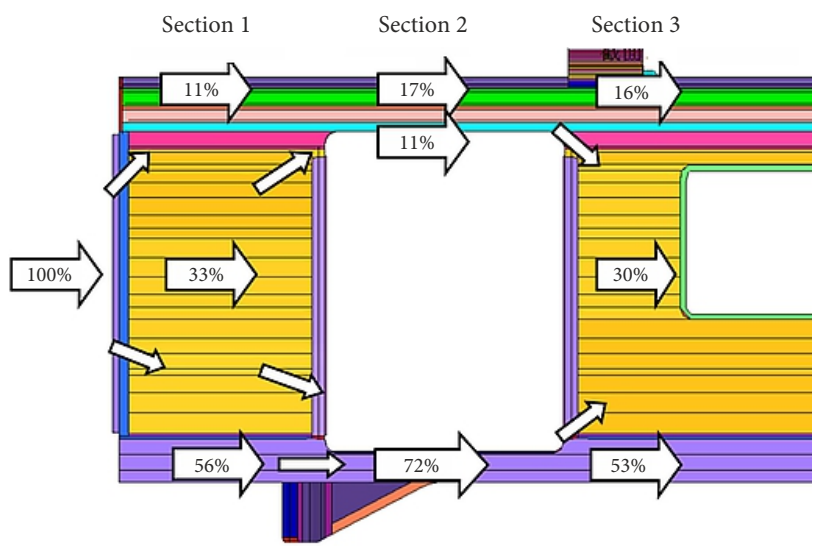

Figure 20. Transfer path distribution of the collision force 
wall in the sidewall integrated module, the collision force transfer rate ranges approximately $11 . .30 \%$; and for the lower underframe, the collision force is directed from the underframe edge beam to the draft and body bolster beam and to the underframe floor, and the collision force transfer rate ranges approximately $50 \ldots 70 \%$.

In terms of the transfer ratio change trend and the collision force, at least, the structural response of a type $\mathrm{C}$ vehicle for this type of collision is similar to that of the type A and type B vehicles.

\subsection{Comparison of results}

The body energy absorption graphs in Figures 5, 11 and 17 indicate that the dynamic collision response of a type $\mathrm{C}$ vehicle is distinctly different from that of a type A vehicle and a type $B$ vehicle. In the same collision scenarios, the type $C$ vehicle attains the maximum value of energy absorption in $0.02 \mathrm{~s}$ and subsequently releases part of the elastic energy that is stored in the body; the total energy absorption value is lower than the total energy absorption value for the two other models. Table 3 lists the energy absorption parameters for the three types of vehicles. The unit energy absorption ratio exhibits a decreasing trend from $\mathrm{A}$ to $\mathrm{B}$ to $\mathrm{C}$, and the type $\mathrm{A}$ vehicle is the best design in terms of maximizing energy absorption. The dominant unit energy absorption components of type A and type B vehicles are the edge beams of the underframe, whereas the endwall is the dominant energy absorption component for the type $\mathrm{C}$ vehicle. Based on the various components of the energy absorption value and the discreteness of the entire body, type $\mathrm{B}$ and $\mathrm{C}$ vehicles exhibit a minimum discreteness value of approximately $140 \mathrm{~kJ} / \mathrm{t}$. This finding indicates that type $\mathrm{B}$ and $\mathrm{C}$ vehicles adopt an integral energy absorption strategy and that their components are involved in the energy absorption. This result is conducive to ensuring the total effectiveness of the structural impact resistance performance during impact and the structural integrity after impact. Although the type A vehicle adopts the individual energy absorption strategy, the structure of the total energy absorption characteristics is weaker than the structure of the total energy absorption characteristics for the type $\mathrm{B}$ and $\mathrm{C}$ vehicles.

Discreteness is calculated as the sum of the absolute value between different parts of a vehicle structure (such as the endwall, sidewall, and roof, as listed in Table 3) and the entire car body; it represents the degree of dispersion for these parts compared with the entire car body.

The results of the comparative analysis are as follows:

1) although the three metro vehicle structures are different, the positions of the large plastic hinge and the deformation of the car body structure and the positions of the large plastic hinge and the deformation are similar during the collision. They primarily occur in the angle of the door, the edge beam, the connection of the draft beam and the end beam and the connection of the draft beam and the body bolster;
Table 3. Energy absorption parameters for three types of vehicles

\begin{tabular}{|l|c|c|c|}
\hline \multirow{2}{*}{\multicolumn{1}{|c|}{ Components }} & \multicolumn{3}{|c|}{ Unit energy absorption } \\
& \multicolumn{3}{|c|}{$[\mathrm{kJ} / \mathrm{t}]$} \\
\cline { 2 - 4 } & $\begin{array}{c}\text { type A } \\
\text { vehicle }\end{array}$ & $\begin{array}{c}\text { type B } \\
\text { vehicle }\end{array}$ & $\begin{array}{c}\text { type C } \\
\text { vehicle }\end{array}$ \\
\hline Entire car body & 38.8 & 36.3 & 34.7 \\
\hline Endwall & 64.3 & 3.0 & 121.6 \\
\hline Sidewall & 14.0 & 33.5 & 26.0 \\
\hline Roof & 18.7 & 33.5 & 20.5 \\
\hline Underframe & 75.1 & 42.4 & 39.0 \\
\hline $\begin{array}{l}\text { Draft beam-body bolster-buffer } \\
\text { beam structure }\end{array}$ & 130.1 & 22.6 & 35.2 \\
\hline Floor structure & 27.2 & 34.9 & 52.4 \\
\hline Edge beam structure & 223.9 & 116.0 & 25.3 \\
\hline Discreteness & 394.6 & 139.6 & 141.9 \\
\hline
\end{tabular}

2) in terms of the key parts of the energy absorption of the vehicle, the underframe structure exhibits the maximum energy absorption of the three types of vehicles. The edge beam, the draft beam and the body bolster achieve the maximum energy absorption for type A and B vehicles, whereas the floor and the edge beam achieve the maximum energy absorption for the type $\mathrm{C}$ vehicle. However, the energy absorption characteristics of the type $\mathrm{C}$ vehicle are relatively poor because the vehicle stores a greater amount of elastic potential energy during the collision process, which is released after the body reaches energy absorption saturation and causes elastic shock and a more significant secondary collision;

3) the transfer path of the collision force is through the roof, sidewall, underframe, and other multilayer structures. The underframe structure is the main collision force transfer path and is the component that best reflects the overall trend of the vehicle collision force characteristics over time. Due to the existence of the sidewalls of the door, a large deformation occurs at the position of the edge beam and the body bolster under the door, and the collision force flow is redistributed in this position, which induces buckling behaviour of the edge beam under a large impact force;

4) the force transfer and distribution have a close relationship with the structural characteristics of the vehicle. The collision force distribution ratio of the various parts and each module energy absorption also have a close correlation.

\section{The lumped parameter model of frontal impact of metro vehicle}

Although the car body structure is one of the main research objects of a vehicle, the objective of design for crashworthiness is to protect the safety of the passengers 
in the vehicle via a controllable deformation mode of the structure. The vehicle body energy absorption should be as large as possible but satisfy the criterion that passengers have adequate space for survival. The analysis results indicate that the vehicle body structural deformation and the dynamic impact stiffness has a close relationship and that the longitudinal force bearing of the different components exhibits a large difference due to different materials and structural forms. In this section, the dynamic stiffness parameters of a vehicle body are analysed, a lumped parameter model of the frontal impact of a metro vehicle is established, and a verification example of the lumped parameter model of frontal impact is discussed.

\subsection{Extraction of dynamic stiffness characteristics of car body}

A vehicle structure undergoes buckling deformation to resist the impact force during the process of a collision. In this paper, the dynamic stiffness characteristic curve of each module of a vehicle body is obtained using the method of vehicle dynamic stiffness extraction in the research by Bojanowski and Kulak (2011). Figure 21 a-c display the pressure collapse deformation stiffness curves of each module for three types of vehicles. Due to the different structural components in a car body, the dynamic stiffness of a car body also differs; however, two stages are generally presented: stiffness enhancement and stiffness weakening. To simplify the stiffness characteristic curves of Figure $21 \mathrm{a}-\mathrm{c}$, we obtain a simplified curve of the stiffness characteristics, as shown in Figure $21 \mathrm{~d}-\mathrm{f}$. After the simplification, the deformation of the car body can be characterized by the stiffness parameters.

\subsection{The lumped parameter model of frontal impact and crashworthiness conceptual design of a car body}

The end structure of a vehicle is the main energy-absorbing part during a crash. To determine whether the response of the end structure is accurate and whether it will directly affect the analysis results of the vehicle, a detailed analysis of the various parts of the end structure should be performed. Based on the stiffness method described in the last section, a complete vehicle spring-mass structural parametric model is established, as shown in Figure 22.

In this figure, $\mathrm{M} 1$ is the small window mass of the sidewall, M2 is the coupler seat mass, M3 is the first segment mass of the roof component module, M4 is the second segment mass of the roof component module, M5 is the first segment mass of the end columns of the sidewall, M6 is the second segment mass of the end columns of the sidewall, M7 is the edge beam mass of the underframe component, M8 is the mass of the body bolster component, and M9 is the mass of the middle body. Because we evaluate only the frontal impact of a vehicle, the longitudi- nal degree of freedom is considered for each mass. The energy-absorbing components or subsystems are represented by spring elements as follows: $\mathrm{K} 1$ is the stiffness of the first section of the upper sidewall, $\mathrm{K} 2$ is the stiffness of the first section of the lower sidewall, $\mathrm{K} 3$ is the stiffness of the first section of the underframe component, $\mathrm{K} 4$ is the stiffness of the first section of the door corner component, $\mathrm{K} 5$ is the stiffness of the first section of the roof component, K6 is the stiffness of the second section of the upper sidewall, $\mathrm{K} 7$ is the stiffness of the second section of the door corner component, K8 is the stiffness of the third section of the door corner component, $\mathrm{K} 9$ is the stiffness of the second section of the underframe component, K10 is the stiffness of the second section of the roof component, $\mathrm{K} 11$ is the stiffness of the third section of the underframe component, $\mathrm{K} 12$ is the stiffness of the fourth section of the door corner component, $\mathrm{K} 13$ is the stiffness of the fifth section of the door corner component, K14 is the stiffness of the third section of the roof component, K15 is the stiffness of the sidewall component, and K16 is the stiffness of the fourth section of the underframe component.

Based on the establishment of a vehicle body structural collision parametric model, we can investigate the parameterization of the vehicle body after impact with a rigid barrier using a positive concept design, optimizing each component stiffness and mass attributes, and improving the crashworthiness of the vehicle. Figure 23 provides the conceptual design flow for a vehicle frontal crash based on the parametric model. The specific steps of the model are as follows:

1) determine the basic information that needs to be designed, such as the vehicle operation condition, equipment mass and service environment;

2) determine the total information of a vehicle body, such as the length, height, and width and the vehicle mass;

3) determine the main energy-absorbing components and the rigid parts of a vehicle, as well as the dynamic stiffness parameters of each module, to establish a spring-mass structural parametric model of the vehicle;

4) conduct a virtual digital simulation analysis using the model to obtain the dynamic response information of the body, such as the key components of the deformation, energy absorption, acceleration/ deceleration, collision section force, and storage information;

5) according to the storage information, determine whether the results satisfy the predefined requirements of the rail vehicle crash safety design criteria; if they are not satisfied, return to the parametric modification until the design criteria satisfy the requirements;

6) follow these steps from the conceptual design stage to the detailed structural design stage. 

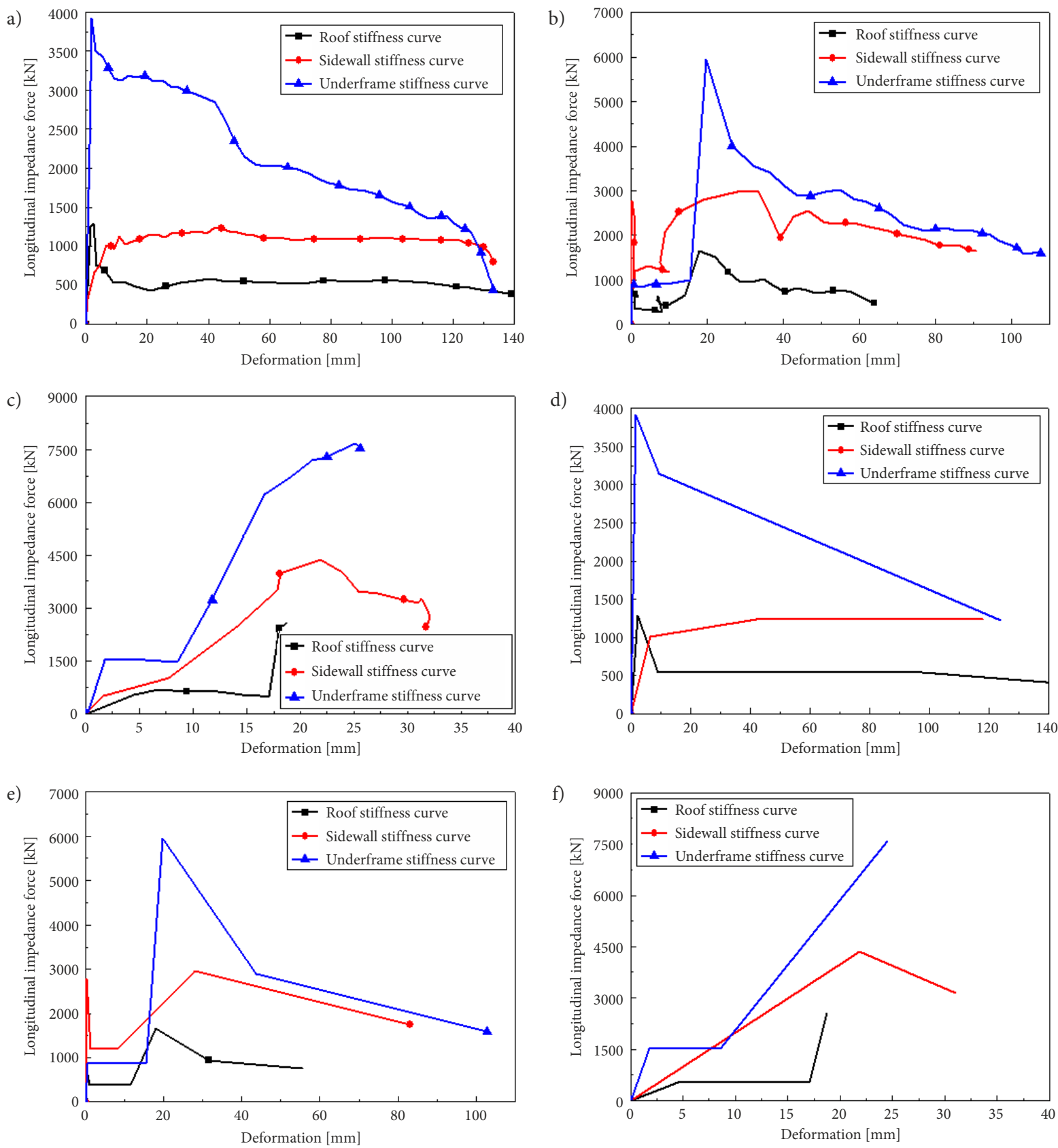

Figure 21. Crushing deformation stiffness curve for three types of vehicles: a - deformation stiffness curve of structural module for type A vehicle; $\mathrm{b}$ - deformation stiffness curve of structural module for type B vehicle; $\mathrm{c}$ - deformation stiffness curve of structural module for type $\mathrm{C}$ vehicle; $\mathrm{d}$ - simplified deformation stiffness curve of structural module for type A vehicle; $\mathrm{e}$ - simplified deformation stiffness curve of structural module for type B vehicle; $\mathrm{f}$ - simplified deformation stiffness curve of structural module for type $\mathrm{C}$ vehicle

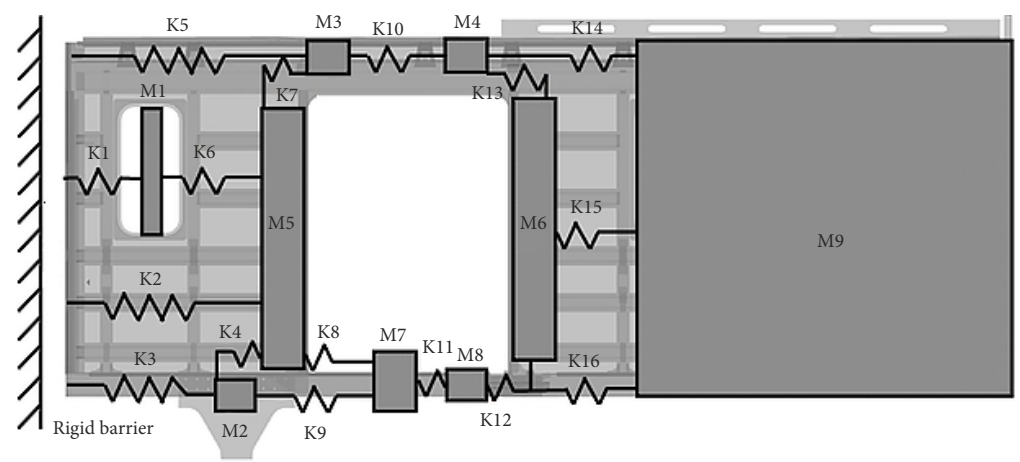

Figure 22. Complete vehicle spring-mass structural parametric model 


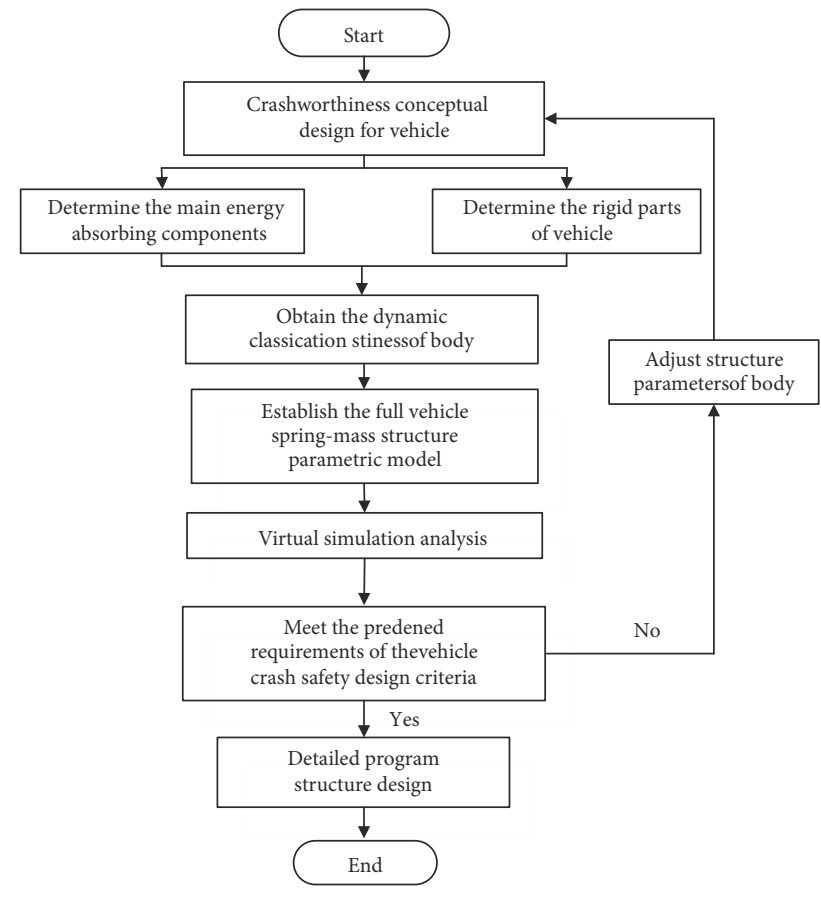

Figure 23. Conceptual design flow for vehicle frontal crash analysis

\subsection{Verification of the lumped parameter model of frontal impact}

To verify the accuracy and reliability of the lumped parameter model of frontal impact, the results of the two models are compared using the same collision scenario.

The lumped parameter model of frontal impact and the FE model of a type $\mathrm{C}$ vehicle are shown in Figure 24. The vehicle collides with a fixed rigid barrier at a speed of $25 \mathrm{~km} / \mathrm{h}$; braking by the train is not considered. The lumped parameter model for frontal impact of a type $\mathrm{C}$ vehicle is established based on Sections 3.1 and 3.2, and
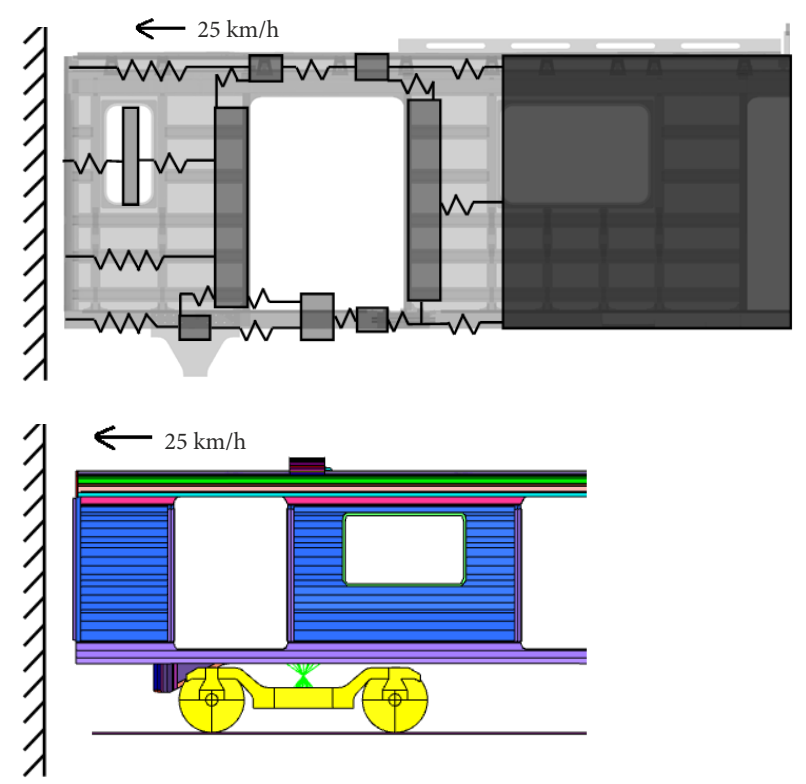

Figure 24. Lumped parameter model of frontal impact and $\mathrm{FE}$ model of type $\mathrm{C}$ vehicle the deformation stiffness curves are obtained from Section 2.

Figure 25 depict a comparison of the speeds, displacements, and deformations, respectively, for a type $\mathrm{C}$ vehicle between the results of the FE model and the lumped parameter model of frontal impact.

These results indicate the following:

1) as shown in Figure 25a, when the vehicle contacts the fixed rigid barrier, the velocity variation curves of the two models (the FE model and the lumped parameter model) are almost identical, predicting a rebound at a speed of $9 \mathrm{~km} / \mathrm{h}$ within $0.15 \mathrm{~s}$, then gradual reduction due to the friction between the wheel and the rail.

2) as shown in Figure 25b, the two models reach the maximum plastic deformation of $300 \mathrm{~mm}$ at the same time. Irreversible deformation occurs in the underframe; with a decrease in the impact velocity, the deformation tends to stabilize. A certain fluctuation is observed at approximately $0.1 \mathrm{~s}$ in the lumped parameter model, which is attributed to the elastic deformation recovery that is established during the process of numerical simulation, and the results fall within a reasonable range.

3 ) as shown in Figure $25 c$, the trend is the same as the trend for the underframe, whereas the amount of deformation is substantially less than the amount of deformation for the underframe; because the bending deformation occurs at the underframe, this finding is consistent with the discussion in Section 2.

For both the velocity and the deformation, the results of lumped parameter model and the FE simulation are consistent, and the effectiveness of the lumped parameter model is verified. The example also shows that the lumped parameter model can be used to evaluate the structure in the conceptual design stage of a vehicle. In addition, the FE simulation model requires approximately $15 \mathrm{~h} 20 \mathrm{~min}$ in the entire simulation process, whereas the calculation time of the lumped parameter model is only $4 \min 30 \mathrm{~s}$, indicating a significant improvement in computational efficiency.

\subsection{Discussion of the conceptual design method for structural crashworthiness}

As shown in Table 1, FE analysis is primarily employed in the subsequent stage of structural design, and an impact test is primarily employed in the verification phase of a real vehicle, whereas the lumped parameter model of frontal impact can provide a simple, efficient and repeatable design verification for a structure in the conceptual design stage. Although the frontal impact model cannot accurately describe the detailed collision response, designers can change the structural parameters (for example, deformation stiffness curves of different parts) according to the requirements. According to Figure 23, designers can effectively and conveniently design a vehicle structure to ensure high safety performance. Note that the simplified deformation stiffness curves are important input condi- 
tions for the lumped parameter model of frontal impact. These curves are initially generated based on the designers' experience; the relative optimization curves are then obtained via repeated calculation and adjustments based on the frontal impact model. The designers can use these curves to design the car body structure.

\section{Conclusions and prospects}

This paper is based on the passive safety protection technology of metro vehicles. Using the transmission mode and transmission path of vehicle collision force flow as the fundamental analysis focus, the dynamic responses of three typical materials for a vehicle impacting a rigid wall were investigated. A research method involving the load transfer path was proposed, and the distribution of the collision force flow in different parts of the vehicle body was analysed. The relationship among deformation, energy absorption and impact force of a train collision was qualitatively presented. By introducing the dynamic stiffness of a vehicle body, a lumped parameter model for frontal impact was established, and the conceptual design method of the train collision was proposed. The main conclusions are as follows:

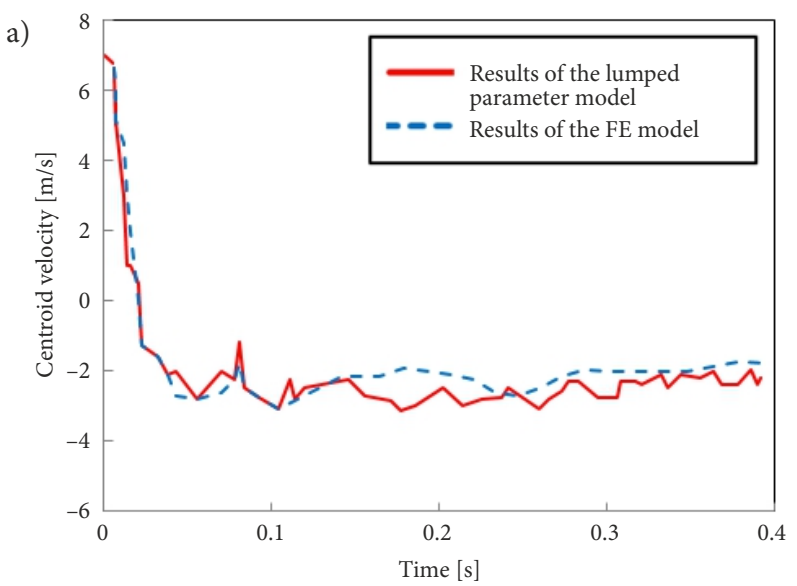

1) the difference analysis of different models in the same collision scene reveals the following results: the under frame is one of the most efficient collision transfer components during the collision process. A comparison of the unit energy absorption ratio indicates that the type A vehicle is better than the other two types of vehicles, whereas the unit energy absorption value of each component and the discreteness of type $\mathrm{B}$ and type $\mathrm{C}$ vehicles are small;

2) due to the existence of the sidewalls of the doors, a large deformation occurs in the position of the edge beam and the body bolster under the door. Simultaneously, the collision force flow is redistributed in this position, which induces buckling of the edge beam under large impact force. This phenomenon occurs in all three vehicle types;

3 ) the lumped parameter model of frontal impact in metro vehicles provides a new method for parametric research on a car body's impact with a rigid barrier by conducting positive conceptual design, optimizing each component's stiffness and quality attributes, and improving the crashworthiness of a vehicle.

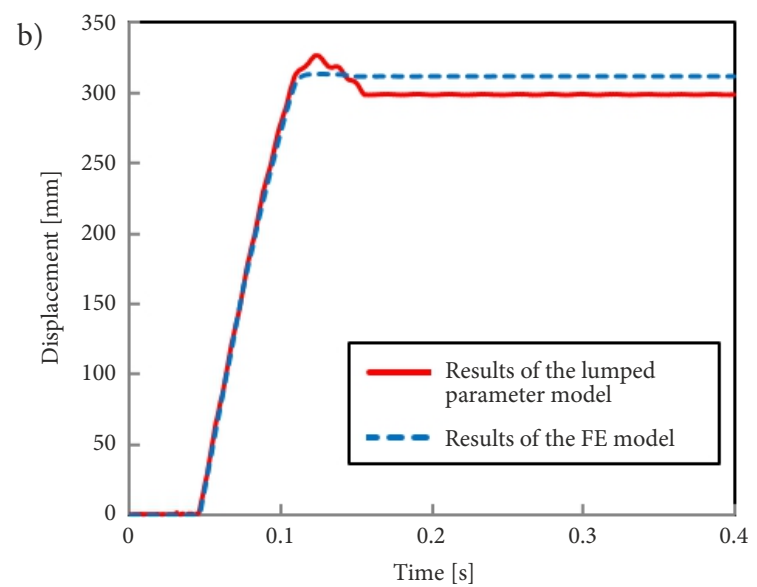

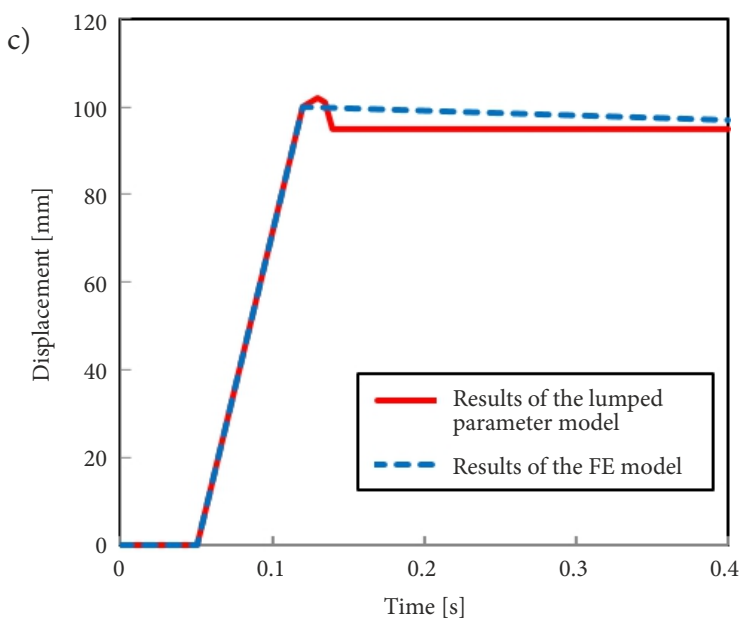

Figure 25. Comparison of the two methods: a - speed change in the gravity center in the two models; $\mathrm{b}$ - displacement of the underframe in the two models; $\mathrm{c}$ - displacement of the roof in the two models 
The train collision response is a complex problem. In this paper, FE simulation is performed to compare the crashworthiness performance of metro structures with three typical materials. The accuracy of the simulation results needs to be verified by experiments. Thus, a scaled or full-scale vehicle crash test platform should be constructed, and the crashworthiness research methods for verifying the accuracy of the simulation models and results should be extended. In addition, rail train collision research efforts should attempt to find a simple method for solving complex engineering problems, using the FE technology and experimental data to improve the establishment of the vehicle frontal crash concentrated parametric model and guide engineering design.

\section{Acknowledgements}

The authors gratefully acknowledge the support of the National Natural Science Foundation of China (51505390), the National Key Technology Support Program (2015BAG12B01-15), and the independent research project of TPL (2014TPL_T04).

\section{References}

49 CFR Part 229. Railroad Locomotive Safety Standards. Code of Federal Regulations (CFR), US.

49 CFR Part 230. Steam Locomotive Inspection and Maintenance Standards. Code of Federal Regulations (CFR), US.

49 CFR Part 231. Railroad Safety Appliance Standards. Code of Federal Regulations (CFR), US.

49 CFR Part 232. Brake System Safety Standards for Freight and other Non-Passenger Trains and Equipment; End-of-Train Devices. Code of Federal Regulations (CFR), US.

49 CFR Part 233. Signal Systems Reporting Requirements. Code of Federal Regulations (CFR), US.

49 CFR Part 234. Grade Crossing Safety. Code of Federal Regulations (CFR), US.

49 CFR Part 235. Instructions Governing Applications for Approval of a Discontinuance or Material Modification of a Signal System or Relief from the Requirements of Part 236. Code of Federal Regulations (CFR), US.

49 CFR Part 236. Rules, Standards, and Instructions Governing the Installation, Inspection, Maintenance, and Repair of Signal and Train Control Systems, Devices, and Appliances. Code of Federal Regulations (CFR), US.

49 CFR Part 237. Bridge Safety Standards. Code of Federal Regulations (CFR), US.

49 CFR Part 238. Passenger Equipment Safety Standards. Code of Federal Regulations (CFR), US.

AAR S-580-2005. Locomotive Crashworthiness Requirements. Association of American Railroads (AAR).

Baykasoğlu, C.; Sünbüloğlu, E.; Bozdağ, S. E.; Aruk, F.; Toprak, T.; Mugan, A. 2012. Crash and structural analyses of an aluminium railroad passenger car, International Journal of Crashworthiness 17(5): 519-528.

https://doi.org/10.1080/13588265.2012.690591

Baykasoğlu, C.; Sünbüloğlu, E.; Bozdağ, S. E.; Aruk, F.; Toprak, T.; Mugan, A. 2011. Railroad passenger car collision analysis and modifications for improved crashworthiness, International Journal of Crashworthiness 16(3): 319-329. https://doi.org/10.1080/13588265.2011.566475
Bojanowski, C.; Kulak, R. F. 2011. Multi-objective optimisation and sensitivity analysis of a paratransit bus structure for rollover and side impact tests, International Journal of Crashworthiness 16(6): 665-676.

https://doi.org/10.1080/13588265.2011.616118

DIN EN 15227:2008. Railway Applications. Crashworthiness Requirements for Railway Vehicle Bodies.

EC. 2002. Commission Decision of 30 May 2002 Concerning the Technical Specification for Interoperability Relating to the Rolling Stock Subsystem of the Trans-European High-Speed Rail System Referred to in Article 6(1) of Directive 96/48/EC. 105 p. Available from Internet:

http://data.europa.eu/eli/dec/2002/735/oj

Gao, G. J.; Tian, H. Q. 2007. Train's crashworthiness design and collision analysis, International Journal of Crashworthiness 12(1): 21-28. https://doi.org/10.1533/ijcr.2006.0138

Hosseini-Tehrani, P.; Bayat, V. 2011. Study on crashworthiness of wagon's frame under frontal impact, International Journal of Crashworthiness 16(1): 25-39.

https://doi.org/10.1080/13588265.2010.499698

Hosseini-Tehrani, P.; Nankali, A. 2010. Study on characteristics of a crashworthy high-speed train nose, International Journal of Crashworthiness 15(2): 161-173. https://doi.org/10.1080/13588260903094418

Hou, S.; Li, Q.; Long, S.; Yang, X.; Li, W. 2007. Design optimization of regular hexagonal thin-walled columns with crashworthiness criteria, Finite Elements in Analysis and Design 43(6-7): 555-565. https://doi.org/10.1016/j.finel.2006.12.008

RSSB. 2012. GM/RT2100: Requirements for Rail Vehicle Structures. Rail Safety and Standards Board (RSSB).

Xiao, S.; Zhang, Z.; Yang, G.; Zhu, T. 2014. Simulation method for couplers and buffers in train collision calculations, Journal of Southwest Jiaotong University 49(5): 831-836. (in Chinese). https://doi.org/10.3969/j.issn.0258-2724.2014.05.014

Xue, X.; Smith, R. A.; Schmid, F. 2005. Analysis of crush behaviours of a rail cab car and structural modifications for improved crashworthiness, International Journal of Crashworthiness 10(2): 125-136. https://doi.org/10.1533/ijcr.2005.0332

Xue, X.; Schmid, F.; Smith, R. A. 2007. Analysis of the structural characteristics of an intermediate rail vehicle and their effect on vehicle crash performance, Proceedings of the Institution of Mechanical Engineers, Part F: Journal of Rail and Rapid Transit 221(3): 339-352. https://doi.org/10.1243/09544097JRRT77 